https://doi.org/10.30843/nzpp.2019.72.325

\title{
Arthropod pests of kiwifruit identified from Chinese language literature
}

Bingqin $\mathrm{Xu}^{1}$ and David A.J. Teulon ${ }^{2,3^{*}}$

${ }^{1}$ The New Zealand Institute for Plant and Food Research Ltd, Private Bag 92169, Auckland, New Zealand

${ }^{2}$ The New Zealand Institute for Plant and Food Research Ltd, Private Bag 4704, Christchurch 8140, New Zealand

${ }^{3}$ Better Border Biosecurity (B3) (www.b3nz.org)

*Corresponding author: David.Teulon@plantandfood.co.nz

References to many other kiwifruit arthropod pests (and diseases) were found as part of a process of searching Chinese language literature to understand the impact of brown marmorated stink bug (Halyomorpha halys; BMSB) and spotted lantern fly (Lycorma delicatula; SLF) on kiwifruit (Actinidia chinensis) and $A$. deliciosa in China. Information on other kiwifruit pests was collated from over 20 Chinese language publications found in searches of the Chinese National Knowledge Infrastructure platform using standard Chinese characters for BMSB, SLF and kiwifruit, and was ranked according to: (1) the number of publications they were mentioned in; and (2) the type of words used to describe their impact. In addition to BMSB and SLF, approximately 50 kiwifruit pests were identified from this process, including a number of species that were unknown to the New Zealand kiwifruit biosecurity community and which may pose a threat to kiwifruit production if they established in New Zealand. This work reinforces the need for searching Chinese databases with Chinese characters in combination with searches in international databases, to ensure comprehensive coverage for biosecurity risk assessment.

https://doi.org/10.30843/nzpp.2019.72.327

\section{An insight into biosecurity plant-disease diagnostics at MPI}

Robert K. Taylor, Merje Toome-Heller, Wellcome W.H. Ho, and Brett J.R. Alexander

Plant Health and Environment Laboratory, Ministry for Primary Industries, PO Box 2095, Auckland 1140, New Zealand

Corresponding author: robert.taylor@mpi.govt.nz

The Mycology and Bacteriology team of the Ministry for Primary Industries' Plant Health and Environment Laboratory is responsible for the identification and verification of all suspected exotic, new, and emerging pathogens affecting plants and the environment in New Zealand. We work in an applied diagnostic environment where results can have significant implications for biosecurity. Sample submissions often result in detection of new to New Zealand fungi and bacteria on plants for which information on fungal and bacterial associations is generally sparse. The complexity of testing required is quite varied with samples being submitted from post entry quarantine (looking for a known pathogen using specific tests), border or surveillance (unknown pathogens requiring multiple tests), or a biosecurity response (scaling up to test large numbers, identification resolution required to strain level). Applied test methods depend largely on the sample type and consist of morphological identification, biochemical testing, pathogenicity testing, serological and molecular techniques, including high throughput sequencing. A profile of our diagnostic work and the most commonly detected taxa and host associations are presented. 